\section{Pseudotumour of the lung caused by Mycobacterium malmoense infection in an HIV positive patient}

\author{
K Yoganathan, $M$ W Elliott, J Moxham, \\ $M$ Yates, A L Pozniak
}

\begin{abstract}
A case of pulmonary Mycobacterium malmoense infection presenting as a pseudotumour of the lung in a severely immunosuppressed HIV infected patient is reported.
\end{abstract}

(Thorax 1994;49:179-180)

In June 1985 a 27 year old homosexual man presented with generalised lymphadenopathy and was diagnosed HIV antibody positive. He remained well until May 1987 when he developed angular cheilitis, folliculitis, and oral hairy leucoplakia. In March 1988 he had been given zidovudine and co-trimoxazole in view of his persistently low CD4 count of less than $200 \mathrm{cells} / \mu \mathrm{l}$. Anaemia and neutropenia developed which resolved after stopping these drugs. Nebulised pentamidine was substituted for co-trimoxazole. He was later rechallenged with low dose zidovudine but his anaemia recurred. His compliance with nebulised pentamidine was poor, and in October 1990 he had an episode of bronchoscopically confirmed Pneumocystis carinii pneumonia. $\mathrm{He}$ was treated with standard high dose co-trimoxazole and made a full recovery.

In May 1991 he complained of left pleuritic chest pain, low grade fever, and weight loss. His chest radiograph showed a confluent area of consolidation in the left upper zone (fig 1), a lateral film indicating involvement of the apical segment of the left lower lobe. His CD4 lymphocyte count at this time was 25 cells/ $\mu$ l. No bacterial pathogens were found in the sputum which was also repeatedly negative for acid fast bacilli. Viral titres and an atypical pneumonia screen were negative. He was initially treated with erythromycin and amoxycillin but, because of persistent symptoms and worsening of his chest radiograph, his treatment was changed to ciprofloxacin $750 \mathrm{mg}$ twice daily and he improved clinically.

A month later he was readmitted with frank haemoptysis. His chest radiograph showed that there was now cavitation within the left

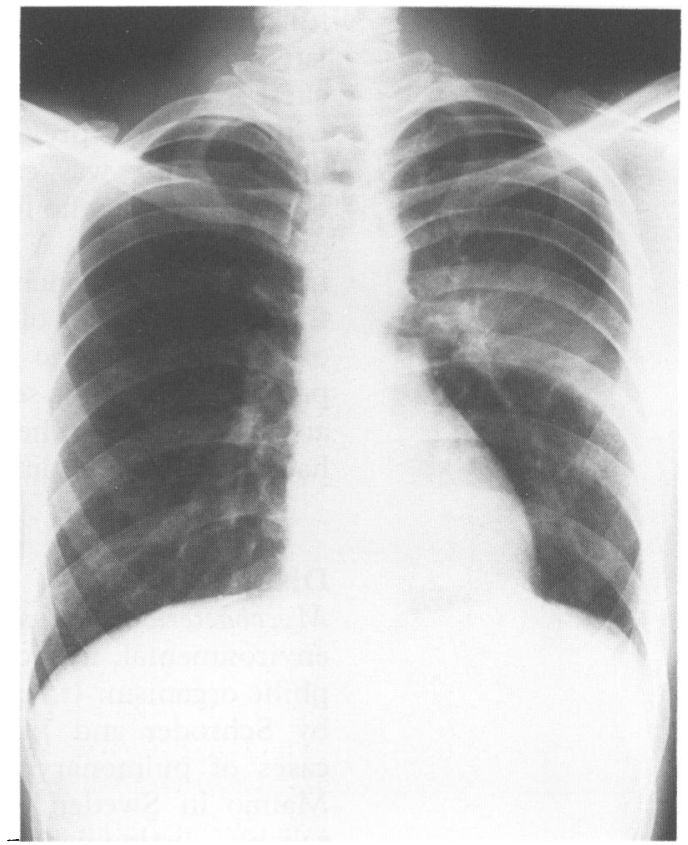

Figure 1 Chest radiograph showing a confluent area of consolidation in the left upper zone.

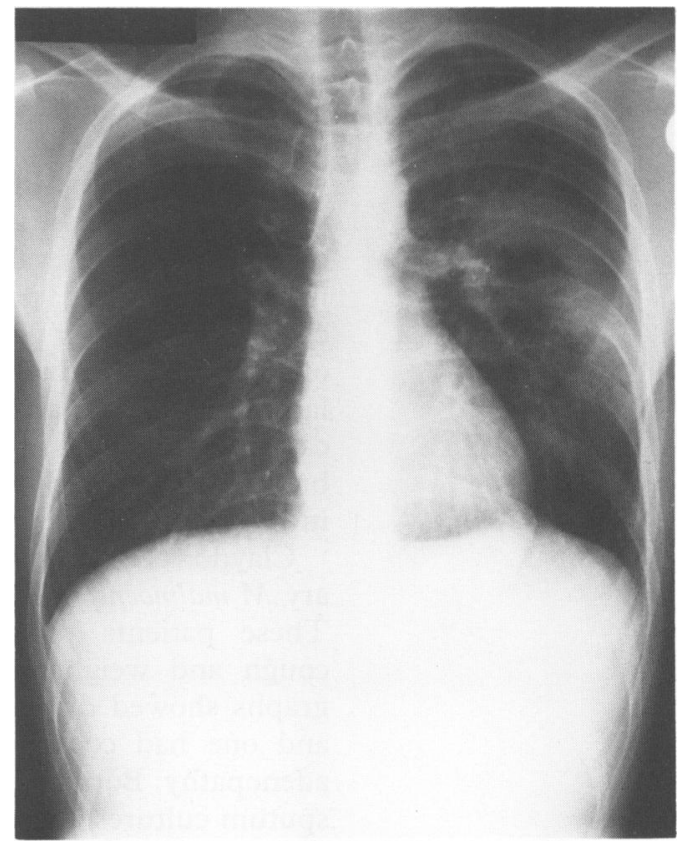

Figure 2 Chest radiograph showing a large cavity in the left upper zone.

upper zone shadowing (fig 2). Bronchoscopic examination showed a white necrotic tumourlike mass occluding the apical segment of the left lower lobe which looked like a carcinoma of the bronchus. Bronchial lavage contained no malignant cells or acid fast bacilli but a biopsy of the "tumour" showed numerous macrophages filled with acid fast bacilli. Mycobacterium malmoense was cultured from the biopsy 
specimen and was sensitive to ethambutol, rifampicin, streptomycin, and ciprofloxacin, but resistant to isoniazid and pyrazinamide. He was treated with rifampicin, ethambutol, and ciprofloxacin and became asymptomatic.

Eight months later, whilst he was continuing full antimycobacterial treatment, he developed left pleuritic chest pain and breathlessness. His chest radiograph was unchanged compared with that of the previous admission. A repeat bronchoscopy was carried out by the same bronchoscopist who found no change from the previous findings. A repeat biopsy was taken from the endobronchial "tumour" occluding the apical segment of the lower lobe. Culture of this biopsy tissue grew $M$ malmoense. The patient's symptoms settled on analgesia alone, and for the present he remains well and free of haemoptysis on antimycobacterial treatment.

\section{Discussion}

Mycobacterium malmoense is a slow growing, environmental, non-chromogenic, microaerophilic organism. It was first described in 1977 by Schroder and Juhlin who reported four cases of pulmonary disease in the town of Malmo in Sweden. ${ }^{1}$ This organism is most reliably distinguished from other mycobacteria by thin layer chromatography of the surface lipids. ${ }^{23}$ It hydrolyses Tween 80 which is an unusual property for pathogenic strains.

Infection with $M$ malmoense usually occurs in middle aged men who have underlying lung disease. ${ }^{45}$ As in infection with $M$ tuberculosis, cough, haemoptysis, and weight loss are the commonest symptoms, although patients can be asymptomatic. ${ }^{5}$ The chest radiograph usually shows unilateral changes which can vary from a patchy infiltrate to multiple thick walled cavities in the upper and mid zones, but a lacework of thin walled cysts with relatively little surrounding parenchymal infiltrate is characteristic. ${ }^{6}$ Our patient had a localised area of consolidation which later developed a single large cavity. The atypical appearance in this case may be due to obstruction of a segmental bronchus or the lack of "tissue response" seen in severe immunosuppression.

Claydon et $a l$ reported two cases of pulmonary $M$ malmoense in HIV positive individuals. These patients presented with productive cough and weight loss. Their chest radiographs showed diffuse bilateral soft shadows and one had coexistent mediastinal lymphadenopathy. Both had acid fast bacilli positive sputum cultures and one had $M$ malmoense in the stool. Standard antituberculous treatment was given but the patients died before any response could be assessed. Their deaths were considered to be unrelated to the $M$ malmoense infection at necropsy.

Although tuberculosis can present with tumour-like masses in the lung, this is, to our knowledge, the first reported case of $M \mathrm{mal}$ moense mimicking bronchial carcinoma endoscopically. Eight months after the first bronchoscopy there appeared to be little change in "tumour" bulk and its growth may have been checked by the prolonged antimycobacterial treatment. Although the patient responded clinically, it is intended to treat him lifelong as he did not achieve any radiological or bronchoscopial response. The optimum treatment for $M$ malmoense infection in HIV antibody positive patients has not been established. In HIV negative patients Banks et $a l^{6}$ obtained the best results with rifampicin, ethambutol, and isoniazid for periods of between 18 and 24 months. Surgical resection which has been successful in four HIV negative patients ${ }^{6}$ would be possible in this case as the disease appears to be localised. Nevertheless, this patient is only mildly symptomatic and the risk of operation probably outweighs any long term benefits as he is severely immunosuppressed. His prognosis is directly related to his degree of immunosuppression and whether or not he develops any life threatening diseases.

Mycobacterium malmoense infection appears to occur at a late stage of HIV disease when the CD4 count is below 50 cells $/ \mu$ l. Unlike the $M$ avium complex, where systemic infection is common and prognosis poor in HIV positive patients, $M$ malmoense appears to be confined to the lung and its course is indolent. Swallowed infected sputum may have caused the positive stool culture in one of the patients reported by Claydon et al. ${ }^{7}$

As the HIV epidemic continues to evolve, clinicians may well be challenged by unusual presentations of atypical mycobacterial disease and face difficult treatment decisions.

1 Schroder $\mathrm{KH}$, Juhlin I. Mycobacterium malmoense. Int $f$ System Bacteriol 1977;27:241-6.

2 Jenkins PA. Mycobacterium malmoense. Tubercle 1985;66:193-5.

3 Connolly MJ, Magee JG, Hendrick DJ, Jenkins PA. Mycobacterium malmoense in the north east of England. Tubercle 1985;66:211-7.

4 Jenkins PA, Tsukamura M. Infections with Mycobacterium malmoense in England and Wales. Tubercle 1979;60:71-6.

5 Roberts C, Clague H, Jenkins PA. Pulmonary infection with Mycobacterium malmoense: a report of four cases. Tubercle 1985;66:205-9.

6 Banks J, Jenkins PA, Smith AP. Pulmonary infection with Mycobacterium malmoense - a review of treatment and Mycobacterium malmoense - a review
response. Tubercle 1985;66:197-203.

7 Claydon EJ, Coker RJ, Harris JRW. Mycobacterium malmoense infection in HIV positive patients. $\mathcal{f}$ Infect 1991;23:195-6. 